\title{
Caracterização semântico-pragmática de tópicos pendentes no português brasileiro
}

\section{Semantic-pragmatic characterization of hanging topics in Brazilian Portuguese}

Tatiane Macedo Costa ${ }^{1}$, Aroldo Leal de Andrade ${ }^{2}$

Doutoranda em Linguística pela Universidade Estadual de Campinas (UNICAMP). tatianemc18@gmail.com.

Pos-doutorando em Linguistica pela Universidade Estadual de Campinas (UNICAMP). aroldo.andrade@gmail.com
RESUMO: 0 objetivo deste artigo é desenvolver uma análise das construç̃̃es de Tópico Pendente e de Deslocação à Esquerda de Tópico Pendente no português brasileiro. Para tanto, adotamos a Teoria da Representação do Discurso Segmentado (SDRT, em inglês), que permite descrever as relações retóricas, e assim, estudar os contextos de uso de certas construções marcadas. 0 corpus que constitui a base de análise dessa pesquisa são as entrevistas publicadas na revista VEJA na década de 1970, bem como os Diálogos entre Informante e Documentador (DID) disponibilizados pelo projeto NURC-SP (Norma Urbana Oral Culta - São Paulo). A partir da análise dos dados, verificou-se uma clara distinção entre o uso das construções sob investigação nos dois corpora. Notou-se que os tópicos pendentes consistem em unidades discursivas em separado, que se relacionam ao contexto por uma relação de subordinação, e ao comentário por enquadramento ou atribuição. Os tópicos pendentes, dessa forma, parecem ser pragmaticamente indistinguíveis dos tópicos de enquadre, pois ambos exercem a função de inaugurar unidades discursivas complexas, de modo a garantir a progressão textual.

Palavras-chave: Tópicos Pendentes; Interface Sintaxe-pragmática; Português Brasileiro.

ABSTRACT: The aim of this paper is to develop an analysis of Hanging Topic and Hanging Topic Left Dislocation in Brazilian Portuguese. To do so, we adopt the framework of Segmented Discourse Representation Theory (SDRT), because it allows one to describe the rhetorical relations, and therefore to study the use contexts of some marked constructions. The corpus which is the basis of analysis of this research are the interviews published in the VEJA magazine in the 1970s, as well as Dialogues between Informant and Documenter (DID) provided by the NURC-SP project (Cultured Urban Linguistic Norm - São Paulo). From the data analysis, it was possible to notice a clear distinction between the uses of the constructions under investigation in the two corpora. We have noticed that hanging topics are discursive units per se, which relate to the context by a subordination relation and to the comment by Frame or Attribution. Hanging topics seem therefore to be pragmatically indistinguishable from frame-setting topics, once both exert the function of inaugurating complex discursive units, so as to preserve textual progression.

KEYwoRDS: Hanging Topics; Syntax-Pragmatics Interface; Brazilian Portuguese. 


\section{Introdução}

existência de tópicos marcados vem sendo bastante debatida na literatura linguística sobre o português, principalmente no que se refere às suas propriedades sintáticas. Em virtude disso, boa parte dos estudos que tratam da questão busca argumentos que justifiquem as diversas possibilidades de introduzir um tópico marcado na estrutura da oração, focalizando, prioritariamente, as restrições quanto ao movimento de constituintes (cf. DUARTE, 1987; GALVES, 1987; 1998, e CALLOU et al., 1993, entre outros).

Apesar de alguns trabalhos no campo formal, a realização de tópicos marcados veio a ser abordada, no Brasil, primeiramente por linguistas funcionalistas. No entanto, os trabalhos pioneiros não enfocam necessariamente as construções marcadas, dadas as suas distintas motivações. Ilari (1986) oferece uma análise dos valores pragmáticos e correlatos prosódicos à articulação tema-rema. Já Pontes (1987) relaciona a distribuição das construções de tópico-comentário à mudança constatada no português brasileiro, envolvendo o apagamento do objeto direto anafórico e o preenchimento do sujeito pronominal.

Ao investigar as estratégias de construções de tópico, Orsini \& Vasco (2007) afirmam que as construções de tópico pendente, denominadas por eles como anacolutos, apesar de serem prototípicas das línguas de tópico, não são tão produtivas como as construções de topicalização e de deslocamento à esquerda no português brasileiro. De acordo com Orsini (2013), dados diacrônicos revelam que a construção de topicalização é mais frequente do que a de deslocamento à esquerda. Quanto aos tópicos pendentes e aos tópicos sujeito, a autora pontua que essas construções, mais recorrentes na modalidade oral, começaram a se inserir no decorrer do século XX em textos escritos de menor grau de formalidade, o que, para ela, é reflexo da mudança de marcação do parâmetro do sujeito nulo e das construções de tópico sujeito e tópico selvagem - em que um oblíquo perde sua preposição.

Diferentemente da classificação das construções de tópico marcado encontrada para o português brasileiro, a categorização dessas construções no português europeu, desenvolvida por Duarte (1987), não inclui os casos de tópico sujeito e tópico selvagem observados no português brasileiro. Segundo esta autora, as construções de anteposição no português europeu são: Tópico Pendente (TP), Deslocação à Esquerda de Tópico Pendente (DETP), Deslocação à Esquerda Clítica (DEC) e Topicalização (TOP), ilustradas respectivamente em (1) a (4) (exemplos de DUARTE, 1987, p. 73-74).

(1) Quanto ao debate de ontem à noite, é forçoso reconhecer que há políticos que falam sobre um país que não conhecem.

(2) O João ... ouvi dizer que ele tinha ido passar férias a Honolulu.

(3) (...) os gerentes, trata-os como se fossem míseros contínuos.

(4) Piscina não sabia que tinha (_).

Em seu estudo, Duarte (1987) não objetiva apresentar quantificações de dados e, apesar de eventualmente estabelecer comparações com o português brasileiro, elas não possuem caráter quantitativo, mas qualitativo. Diante disso, estabelece alguns critérios no intuito de diferenciar as construções de anteposição. Dentre eles, Duarte (1987) pontua que essas construções exibem distinções quanto ao seu grau de sintatização, devido ao tipo e à força das conexões existentes entre o constituinte com a função de tópico e os elementos internos à sentença. ${ }^{1}$

${ }^{1}$ Em um exemplo semelhante a (2), como "O João, ele saiu", em que a posição de base do tópico é o sujeito da oraç̃o matriz, similarmente terímos uma DETP, porém a distinção não é relevante dada sujeito da oração matriz, similarmente teriamos uma DETP, porém a distinção não é relevante, dada a inexistência de clíticos nessa posição. De acordo com Costa (2010), - que acredita haver uma possível em português europeu, com pausa entre o tópico e o sujeito. 
Vê-se, portanto, que essas considerações de ordem formal nada dizem sobre a relativa abundância de dados com tópicos marcados no português brasileiro. Por isso, a hipótese deste trabalho é que, independentemente de serem abundantes ou não no português brasileiro, tais construções continuam a ser vinculadas a contextos específicos de uso. ${ }^{2}$

Diante disso, o presente estudo se propõe a discutir questões relacionadas a duas construções de tópicos marcados no português brasileiro: a construção de Tópico Pendente (TP) e a Deslocação à Esquerda de Tópico Pendente (DETP) (quando se fizer referência a ambas as construções, utilizamos o termo "anteposição pendente"). A escolha das referidas construções se deu pelo fato de elas apresentarem um menor grau de sintatização e, consequentemente, serem mais difíceis de caracterizar a partir de um estudo que não leve em conta questões de interface. Ademais, dado que não é possível encontrar na literatura trabalhos que façam um levantamento e análise específica do uso de tais construções, este estudo pretende oferecer uma contribuição para sua caracterização textual/discursiva. Para tanto, assume-se o quadro teórico da SDRT (Segmented Discourse Representation Theory). Ainda assim, textos das tradições formal e funcional serão levados em consideração, haja vista o crescente interesse pela estrutura informacional nessas duas vertentes da linguística.

0 presente trabalho ${ }^{3}$ está organizado da seguinte maneira: na seção 1 , apresentamos uma revisão de alguns estudos existentes sobre as construções de TP e DETP em português, com enfoque nas observações de Duarte (1987) sobre seu uso no plano textual; na seção 2, incluímos os pressupostos teóricos do trabalho; na seção 3, a metodologia para o estudo empírico; na seção 4,

\footnotetext{
2 Cumpre observar que o grau de sintatização é um critério que observa a relação formal entre tópico e comentário, sem questionar a diferença quantitativa de uma dada construção.

3 Este artigo é fruto de um trabalho de qualificação de área apresentado ao Instituto de Estudos da Linguagem na Universidade Estadual de Campinas (IEL/UNICAMP) como requisito parcial para a obtenção do título de Doutor em Linguística. Tal qualificação foi desenvolvida pela primeira autora deste artigo e orientada pelo segundo autor.
}

apresentamos os resultados do estudo baseado em corpus; na seção 5, uma discussão, elaborando teoricamente alguns dos resultados encontrados à luz de questões teóricas. Finalmente, apresentamos as considerações finais, onde se faz uma breve consideração sobre contributos do presente texto para os casos de anteposição pendente no português.

\section{As construções observadas}

\subsection{A Topicalização Pendente}

O termo tópico pendente ${ }^{4}$, também conhecido como nominativus pendens na gramática latina, foi cunhado por A. Grosu e designa uma construção que serve principalmente para promover um NP para o status de tópico, sendo desprovido de marcação de caso (cf. Cinque, 1977).

Ao investigar a construção de topicalização no português europeu, atentando-se a questões concernentes à regência, à ligação e às condições sobre o movimento, Duarte (1987) defende que a construção de TP, exemplificada em (1) na seção anterior, exibe um menor grau de sintatização, uma vez que não apresenta "qualquer lacuna ou elemento pronominal ocorrendo no comentário que seja referencialmente dependente do constituinte com a função de tópico" (DUARTE, 1987, p. 74)..$^{5}$ No entanto,

${ }^{4}$ Cumpre ressaltar que não há consenso na literatura sobre os requisitos semântico-pragmáticos suficientes para identificar um tópico, havendo definições que se baseiam nas seguintes noções: (i) o constituinte tema da sentença (aboutness topic); (ii) o constituinte com informação dada; (iii) o constituinte não-focal, numa abordagem de foco/pressuposição ( $c f$. Casielles-Suárez, 2004). Por essa razão, o estudo baseado em construções de tópico marcado pode ser especialmente útil, ao fornecer dados concretos sobre a expressão de tais elementos.

${ }^{5}$ Note-se que, considerando a caracterização tradicional de que somente o TP permite a ocorrência de uma expressão introdutora, tem-se de considerar a possibilidade de um resumptivo ocorrer dentro de uma oração encaixada:

(i) a. Quanto ao Paulo, o João disse que ele ainda não sabe de nada.

b. Quanto ao Paulo, o João disse que a Maria o mandou pastar. Isso implica dizer que a conectividade pode ser encontrada com TPs em determinadas condições. Além

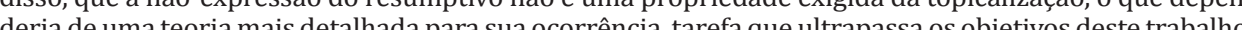


esse tipo de tópico obedece a uma condição de relevância que pressupõe haver um nexo semântico entre o tópico e o comentário. Por exemplo, em (1) infere-se que o "debate" referido no tópico se relaciona com "políticos" (que dele participaram).

No plano textual, Duarte (1987) destaca o fato de o TP incluir um tópico que é utilizado como um elemento de ligação entre o assunto da sequência anterior e o assunto da sequência seguinte. Se analisarmos o exemplo (5), de DUARTE (1987, p. 73), apresentado abaixo, veremos que, conforme pontua a autora, é mais plausível que o discurso subsequente seja sobre a praia de Arrábida do que sobre praias em geral:

(5) Bom... praias, adoro a Arrábida.

Desse modo, a construção de TP operaria como um elemento que permite a transição entre tópicos discursivos distintos.

\subsection{A Deslocação à Esquerda de Tópico Pendente}

Duarte (1987) defende que a DETP apresenta, além de conectividade referencial, uma conectividade sintática ${ }^{6}$ entre o tópico e a expressão nominal inserida no comentário, ou seja, há traços de concordância (pessoa, número ou gênero) entre o tópico e a expressão nominal que o retoma. Nesse tipo de construção, a expressão nominal conectada referencialmente com o tópico pode ser ou um pronome forte ou clítico sem conectividade casual ou um epíteto (exemplos de DUARTE, 1987, p. 73; 77):

(6) a. A Maria, encontrei ontem aquele amigo dela que faz cinema. b. A Maria ... encontrei ontem um amigo dessa cretina.

\footnotetext{
${ }^{6}$ Segundo Duarte (1987), é possível encontrar na construção de DETP um maior grau de sintatização do que aquele encontrado na construção de TP, pois o tópico e o termo correferente a ele apresentam conectividade de traços. Assim, em (6a), tanto A Maria como dela possuem os traços \{fem.; $3^{a}$ pessoa do singular\} e, em (6b), A Maria e dessa cretina apresentam os traços \{fem; 3 a pessoa do singular\}.
}

No plano textual, a autora afirma que a DETP pode indicar a alteração do assunto relacionado com o tópico da sequência anterior ou ser utilizado como uma estratégia de resposta a uma pergunta sobre o tópico. Diante disso, um contexto adequado para (6b) seria, segundo Duarte (1987, p. 80), uma pergunta como a seguinte:

\section{(7) E a Maria? O que é [que] se passa com ela?}

As características apontadas por Duarte (1987) parecem repercutir estudos funcionalistas sobre diálogos e cadeias temáticas. Num estudo que recupera resultados dessas pesquisas, Givón (2001) observa que a Deslocação à Esquerda envolve uma ruptura temática, que pode ocorrer num mesmo turno ou, especificamente, indicar uma tomada de turno.

Apesar da afirmação que supõe diferenças quanto à conectividade sintática, que segundo Duarte (1987) estaria presente na DETP e ausente no $\mathrm{TP}$, a autora salienta que ambas as anteposições pendentes se assemelham quanto ao fato de não apresentarem conectividade temática e casual entre o tópico e a lacuna ou elemento correferente. ${ }^{7}$ Além disso, essas construções de tópicos marcados ocorrem tipicamente em contextos de frases-raiz e não permitem multiplicidade de tópicos deslocados à esquerda.

\section{Pressupostos teóricos}

Nesta seção, observamos os pressupostos teóricos que guiaram a pesquisa sobre as construções de anteposição pendente. Como já mencionado,

${ }^{7}$ A conectividade temática e casual dizem respeito, respectivamente, à igualdade de papel temático e Caso entre o tópico e o item que o retoma. Em uma língua como o português brasileiro, a marcação morfológica de Caso só visive pelo fato o tópico disso, pelo fato de o tópico ocorer en una fentifica de sujeito. 
adotamos a SDRT, que, segundo Busquets, Vieu \& Asher (2001), resulta de duas tradições: a semântica formal e a análise do discurso. Dessa última, a SDRT se interessa em identificar os segmentos discursivos e as relações retóricas entre essas unidades, que podem ser classificadas em dois tipos básicos. Esses três tópicos serão objeto das subseções a seguir.

Antes de passar a isso, observamos que a importância de se fazer uma relação entre estrutura informacional e estrutura discursiva deriva do fato de que a segunda organiza todas as relações semânticas e pragmáticas, incluindo a resolução de anáforas, as pressuposições, assim como outros fenômenos. Portanto, o componente informacional deve sofrer interferência da estrutura discursiva, ou até mesmo ser guiado por ela.

\subsection{Unidades discursivas}

0 primeiro passo no sentido de proceder à análise da estrutura retórica de um texto consiste na identificação de suas unidades discursivas. Uma Unidade Discursiva Elementar (UDE) contém, via de regra, uma proposição independente - $c f$. (8a). Seguindo a orientação de Müller et al. (2012), noutros casos a UDE pode se compor de uma oração subordinada, ou coordenada, mesmo que compartilhem o mesmo sujeito - $c f$. respectivamente (8b) e (8c); ${ }^{8}$ as UDEs são marcadas entre colchetes, e os exemplos se inspiram nos apresentados em Müller et al. (2012):

(8) a. [Trezentos nacionalistas bascos protestam em Paris.]

b. [Ele deveria avisar] [se vem ou não.]

c. [Ela mediu] [e planejou cada cômodo da casa.]

${ }^{8}$ Orações subordinadas não-finitas são marcadas em separado, mas as orações em que há uma perífrase, i.e. em que os verbos formam um predicado complexo, há uma só UDE:

(i) a. [Ela saiu] [para encontrar-se com seu namorado].

b. [Ela tentou fugir]
Casos de sintagmas apositivos - $c f$. (9a) - ou adverbiais, esses últimos desde que expressos por nominais com força eventiva ou adverbiais deslocados, - respectivamente em (9b) e (9c) - também são considerados como unidades discursivas.

(9) a. [Mikhail Saakachvili, [o jovem presidente georgiano,] devia agir para salvar seu governo.]

b. [A vila tinha caído na escuridão] [por causa de uma interrupção no fornecimento de energia.]

c. [Um ano depois,] [a equipe foi rebaixada para a segunda divisão.]

Outras regras de segmentação não são propriamente relevantes para discussão a ser feita a seguir. Uma discussão sobre a adequação de se incluir (9c) como UDE será feita na seção 5.

Além das UDEs, há que se considerar a existência de Unidades Discursivas Complexas (UDCs), que servem para conferir coerência temática e retórica a um texto, da mesma forma que as UDEs. Como se pode prever, uma UDC envolve conexões entre constituintes maiores, pois inclui duas ou mais UDEs. Como indicam Asher et al. (2011), uma UDC oferece o escopo correto para determinadas instanciações de relações retóricas, o que é necessário no caso de encaixamentos complexos: em [O João disse $]_{a}$ [que o Pedro afirmou] $]_{b}$ [que a Patrícia estava doente], há uma UDC que inclui $[\mathrm{b}+\mathrm{c}]$, relacionando-as conjuntamente à UDE [a] (observe-se que uma relação distributiva $(a, b)$; $(b, c)$ não daria a semântica correta para a frase em questão).

\subsection{Relações retóricas}

No quadro teórico da SDRT, assume-se que as unidades discursivas (UDEs ou UDCs) são vinculadas entre si por meio de relações retóricas. 
No seu modelo original, a SDRT propunha que as relações retóricas podem ser definidas semanticamente como tipos de atos de fala ( $c f$. ASHER \& LASCARIDES, 2003, p. 31). Seguindo a abordagem searleana, atos de fala são uma parte essencial do significado, e a compreensão sobre que atos de fala foram realizados é essencial para uma comunicação de sucesso.

Em termos práticos, de acordo com Reese et al. (2007), efeitos semânticos e pistas linguísticas superficiais oferecem juntos evidência suficiente de que duas unidades discursivas estão unidas por uma dada relação. Por exemplo, Atribuição $(\alpha, \beta)$, implica uma semântica que relaciona o conteúdo de um ato comunicativo, dado em $\beta$, ao agente deste ato, dado em $\alpha$. Segundo Reese et al. (2007), tal relação é do tipo subordinativa, intensional e portanto não-verídica à direita, isto é, a sentença encaixada $\beta$ é discursiva e estruturalmente subordinada à sentença matriz $\alpha$ e o que foi dito não pode ser tomado como um fato. Um exemplo desse tipo de relação retórica ocorre em [O sindicato disse] [que a proporção dos ajustes era inadequada], em que o verbo de atitude proposicional disse em [a] é uma pista linguística dessa relação.

Neste trabalho, assumimos a lista de relações retóricas assumidas em Müller et al. (2012), que pode ser representada de forma didática como na Tab. 1. É importante informar o leitor dessa lista, já que, a partir de desenvolvimentos mais recentes da SDRT, novas relações retóricas foram admitidas, em parte como resultado do trabalho empírico sobre dados de corpora anotados discursivamente, como o ANNODIS. ${ }^{9}$

\footnotetext{
O ANNODIS é um corpus do francês, anotado discursivamente, e pode ser acessado em http://redac. univ-tlse2.fr/corpus/annodis/.
}

Tabela 1 - Características das relações retóricas

\begin{tabular}{|c|c|c|}
\hline Veridicalidade ${ }^{\text {Estruturação }}$ & Coordenação & Subordinação \\
\hline Verídicas & $\begin{array}{c}\text { Condição, } \\
\text { Continuação, Narração, } \\
\text { Resultado, } \\
\text { Paralelo }\end{array}$ & $\begin{array}{l}\text { Background, Enquadramento, } \\
\text { Comentário, Explicação, } \\
\text { Elaboração, Flashback, } \\
\text { E-Elaboração,* } \\
\text { Localização temporal }\end{array}$ \\
\hline Não-verídicas & $\begin{array}{l}\text { Consequência, } \\
\text { Alternância }\end{array}$ & $\begin{array}{l}\text { Atribuição, } \\
\text { Finalidade }\end{array}$ \\
\hline
\end{tabular}

*E-elaboração significa "elaboração de entidade" e liga dois elementos, sendo que o segundo explicita uma propriedade de uma das entidades implicadas no primeiro elemento. Pode-se aplicá-la especialmente ao caso de apostos, como o que se observa em (9a) acima.

Fonte: Elaborado a partir de Afantenos \& Asher (2010); Müller et al. (2012).

Como se pode notar, nem todas as relações indicadas acima indicam atos de fala, como propunham originalmente Asher \& Lascarides (2003): várias das relações de subordinação indicadas, como Background, Enquadramento e Localização temporal, parecem ser subespecificadas quanto a esse aspecto.

Diante disso, indicamos a leitura do manual de Müller etal. (2012) ao leitor interessado em acessar as definições de tais relações. A seguir, explicitamos a classificação entre relações de 'coordenação' e de 'subordinação' discursiva, visto que essa propriedade permite a estruturação das unidades discursivas e sua representação simplificada em gráficos discursivos.

\section{3 'Coordenação' e 'subordinação’ discursiva}

As teorias de representação do discurso mais conhecidas, como a Rhetorical Structure Theory (RST) - cf. Mann \& Thompson (1988) - e a Segmented Discourse Representation Theory (SDRT) - cf. Asher \& Lascarides (2003) - compartilham o pressuposto básico da possibilidade de computar estruturas hierárquicas a partir das relações retóricas. Na RST, isso se reflete na diferença entre núcleo e satélite, o primeiro representando uma 
informação mais importante do que o segundo. Já a SDRT trabalha com a tipologia 'coordenação' e 'subordinação' no nível discursivo.

A distinção entre 'coordenação' e 'subordinação' discursiva tem, para Asher \& Vieu (2005), uma motivação intuitiva, segundo a qual algumas partes do texto exercem um papel subordinativo com relação às demais. Exemplificando de maneira simples, os autores argumentam que a sentença principal de um parágrafo oferece àquele parágrafo a sua ideia principal, enquanto que as outras sentenças nesse mesmo parágrafo deverão elaborar ou dar suporte à ideia com argumentos. Caso esses outros pedaços de informação apareçam no mesmo nível de detalhe em relação à sentença principal, haverá uma relação de coordenação entre eles e, consequentemente, uma relação de subordinação entre eles e a sentença principal. A partir da identificação do tipo das relações retóricas em causa, podem-se elaborar representações gráficas, como a que aparece na Fig. 1, em que as relações de subordinação são indicadas pelas setas verticais ou oblíquas e as relações de coordenação são indicadas pelas setas horizontais (o exemplo original e a figura foram extraídos de Asher \& Vieu, 2005, p. 592-3; a tradução livre é nossa):

Podem-se identificar as seguintes relações em (10): as sentenças (10c-d) elaboram sobre a refeição mencionada em (10b), que, por sua vez, elabora sobre a noite mencionada em (10a). A sentença (10e) também elabora sobre como foi a noite, mas, contrariamente a (10c-d), não elabora sobre o jantar; em vez disso, forma uma narrativa com (10b). Então, (10e) não deveria ser considerada parte do mesmo segmento que (10c-d).

As sentenças (10f/f'/f") não estão representadas na Fig. 1 porque se prestam a indicar possibilidades de conexão de novas UDEs à estrutura preexistente em (10a-e). Assumindo-se a Restrição da Fronteira Direita, que prediz que somente constituintes discursivos localizados na fronteira direita do gráfico podem oferecer pontos de ligação para novos constituintes, consegue-se explicar a incoerência de uma ligação do tipo $(10 \mathrm{a} \rightarrow 10 \mathrm{f})$, pois

Figura 1 - Representação discursiva de (10a-e).

(10) a. John had a great evening last night.

b. He had a great meal.

c. He ate salmon.

d. He devoured lots of cheese.

e. He then won a dancing competition.

f. ? Then he had a great dessert.

f. \# It was a beautiful pink

f'. John had lots of fun.
(10) a. John teve uma ótima noite ontem.

b. Ele comeu uma ótima refeição.

c. Ele comeu salmão.

d. Ele devorou pedaços de queijo.

e. Ele, então, venceu uma competição de dança.

f. ? Então, ele comeu uma ótima sobremesa.

f. \# Era de um rosa bonito.

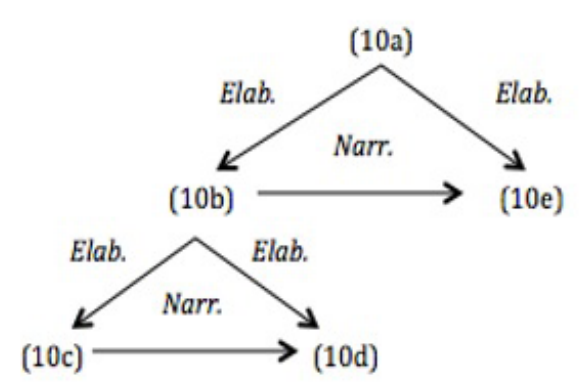

f". John se divertiu bastante. 
comer uma sobremesa (10f) está subordinado ao evento refeição (10b), mas como nem (10d) nem (10b) estão na fronteira direita, o pronome he em (10f) não poderia ser ligado em nenhum desses pontos para elaborá-la. Além disso, a referida restrição da fronteira direita, somada a algumas restrições de acessibilidade adicionais, explica também a impossibilidade da ligação $\left(10 \mathrm{a} \rightarrow 10 f^{\prime}\right)$ : não seria possível identificar o referente de it em (10f') com o salmão em (10c), pois uma ligação direta (10a $\left.\rightarrow 10 f^{\prime}\right)$ ignoraria a refeição (10b), que está sendo elaborada em (10c) e em (10d), impossibilitando, portanto, que esta se torne um elemento anafórico para (10f'). Por outro lado, Asher \& Vieu (2005) argumentam que, se considerarmos o discurso (10a-e $\rightarrow 10 \mathrm{f}$ "), assumindo que divertir-se possui um componente anafórico, seria possível identificar seu antecedente ora pela eventualidade introduzida no primeiro constituinte (uma noite agradável), ora pela eventualidade introduzida no nível mais baixo (uma competição de dança).

\section{Metodologia}

O processo de classificação das relações retóricas envolvendo as construções de anteposição pendente, (DETP) e (TP), tornou-se possível através da identificação de diversos fatores sintáticos, semânticos e pragmáticos.

A partir dos critérios estabelecidos por Duarte (1987), considerou-se aqui como uma construção de TP todos os elementos diferentes do sujeito que, localizados à esquerda da oração, apresentam como principal característica a ausência de relação argumental com o verbo, identificados ou não por uma expressão introdutora, tal como se pode verificar nos exemplos (11) e (12):

(11) agora... assim.... mas de uma forma geral eu acho que TOdo... todas as:: os ramos da Medicina são têm... éh um há há um equilíbrio de procura... do dos moços e das moças que se formam em Medicina... acho que há um equilíbrio... pela especialização... quer dizer (o meu) eu sou meia leiga pra falar nisso mas eu acho... // pelo que a gente ouve falar eu acho que é assim... acho que há equilíbrio... agora quanto a Dire::ito... eu sou muito mais leiga do que eu sou em em Medicina ((risos)) (NURC-SP, inquérito 251).

(12) (...) as minhas viagens na Europa foram essencialmente de:: avião... com exceção de uma viagem que eu fiz de::... de VeNEza a FloRENça e depois de Florença a Roma de TREM... eu resolvi dispensar o avião eu resolvi viajar de trem porque naquela época do ano o avião não descia em Florença então eu tinha que descer em Piza e pegar uma condução em Piza e ir até Florença então::... deliberei:: viajar de de::: de trem... melhoramentos públicos... o que mais me::: impressionou foi o do metrô... em Paris e o do metrô em::... em Londres... que são realmente::.... verdadeiros mo/monumentos de:::: trânsito né? porque isso resolveu... o problema ou:: pelo menos amenizou o problema que:: aqui em São Paulo existe muito grave que é o do congestionamento (NURC-SP, inquérito 137)

Ainda seguindo as observações de Duarte (1987), foram considerados casos de DETP as ocorrências em que o elemento deslocado apresentava, além da conectividade referencial, uma expressão nominal no comentário, resumptiva do tópico, como em (13):

(13) uma profissão por exemplo que eu acho... TOtalmente desvalorizada hoje é de professora primária... professora primária (é) ela é TOtalmente desvaloriZAda incu/inclusive o nível... o:.... nível cultural dela é considerado baixo (NURC-SP, inquérito 251) 
Foram analisadas 109 ocorrências dos dois tipos de tópico pendente, das quais 56 correspondem a dados coletados em entrevistas da revista VEJA e 53 correspondem a dados coletados em inquéritos do tipo Diálogo entre documentador e informante (DID), disponibilizados pelo NURC-SP. ${ }^{10}$ Com vistas à uniformização dos corpora, os dados da revista VEJA se restringiram a entrevistas concedidas na década de 1970 por entrevistados nascidos no Estado de São Paulo, tal como os informantes do projeto NURC.

Apesar de haver diferenças de registro entre os corpora, ambos se aproximam em termos de gênero textual, por compartilharem o mesmo objetivo e modalidade: entrevistas orais. A escolha metodológica de realizar buscas de dados tanto nos textos do NURC-SP como na revista VEJA se deu devido à possibilidade de ampliar o número de ocorrências sob análise. Ademais, tal decisão possibilitou que pudéssemos observar a influência do tipo de registro (mais ou menos formal) sobre a realização do fenômeno.

0 tratamento dos dados envolveu como primeira fase sua classificação em uma tabela Excel, incluindo aspectos como: ocorrência transcrita (parágrafo com a frase incluindo TP ou DETP), tipo de construção, elemento introdutor (se for o caso), definitude do constituinte anteposto e seu grau de ativação (novo, velho ou acessível).

A segunda fase do tratamento dos dados consistiu na análise de um grupo aleatório de ocorrências, nas quais os textos foram segmentados em UDEs e suas relações retóricas foram classificadas a partir da metodologia descrita por Müller et al. (2012). As UDEs foram identificadas com numerais e as UDCs com letras do alfabeto, a fim possibilitar em seguida a identificação das relações retóricas entre elas. Neste trabalho, nos restringimos apenas às estruturas discursivas mais amplas até o nível do parágrafo, devido à natureza

${ }^{10}$ As entrevistas da $V E J A$ foram transcritas a partir do acervo digital disponível na página: http://veja.abril.
com.br/acervodigital/home.aspx . Os dados do NURC foram extraídos de Urbano (1988). As tabelas que formam o grupo de dados podem ser disponibilizadas aos interessados. dos corpora analisados (entrevistas). Assim, uma análise macroestrutural de textos, envolvendo seções e vários parágrafos, não foi realizada por ultrapassar os objetivos deste trabalho.

Sobre a questão da identificação das unidades discursivas, fazemos uma breve observação, tendo em vista a possibilidade de outros estudos buscarem replicar a metodologia aqui utilizada. As relações retóricas, segundo Müller et al. (2012), podem ser explicitamente indicadas por um marcador discursivo, tal como porque em (14a), ou implícita, como se pode verificar em (14b) (exemplos adaptados de MÜLLER et al., 2012, p. 10): ${ }^{11}$

(14) a. [A taxa de desemprego despencou em 2008]_1 [porque há menos ativos]_2

b. [0 time perdeu terrivelmente ontem.]_1 [Ele tinha muitos feridos]_2

Nos casos em que a ligação discursiva é implícita, a compreensão de que há um ato de fala do tipo "explicação" é essencial para que se obtenha a coerência discursiva local. Diante disso, uma relação pode ser caracterizada tão somente por sua semântica, desde que seja possível detectar claramente a intenção do autor em expressá-la.

\section{Resultados}

Nesta seção, vamos analisar primeiramente questões de ordem quantitativa e, em seguida, nos ateremos a questões de ordem qualitativa.

${ }^{11}$ Os manuais de anotação retórica comumente apresentam marcadores discursivos como indícios de ocorrência de determinadas relações retóricas. Contudo, nem sempre tais marcadores são fiáveis, devido a uma ambiguidade intrínseca ou a erros de performance. 


\subsection{Aspectos quantitativos}

Com respeito à distribuição geral das construções, a análise dos dados revelou, tal como era esperado, que ambas ocorrem de maneira mais regular no corpus NURC (cf. Gráfico 1). Os dados da revista VEJA, por outro lado, apresentaram um número bastante inferior de ocorrências de DETPs em relação aos casos de TPs. A constatação de que tais ocorrências podem ser encontradas mesmo em textos como entrevistas formais, passíveis de edição, revela que elas não são alvo de estigma no português brasileiro. Contudo, pode-se imaginar que a DETP ocorre em menor frequência nos dados da revista VEJA devido à repetição sintática que essa construção sugere. Isso pode ter tido um efeito de monitoramento na fala dos próprios entrevistados ou até mesmo de modificação por parte dos editores. Contudo, não podemos aferir a conduta dos editores a partir de evidências puramente textuais.

Gráfico 1 - Distribuição das ocorrências de TP e DETP nos dois corpora.

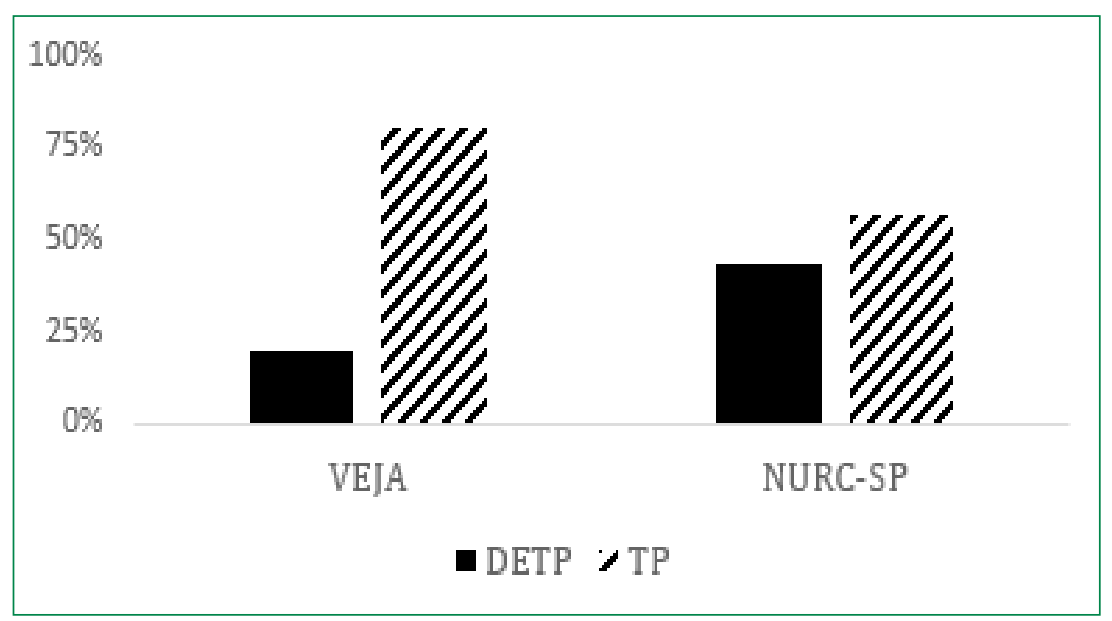

Outro aspecto quantitativo relevante diz respeito ao uso de expressões introdutoras de tópico, que são encontradas tão somente com a construção de TP. É importante notar que, diferentemente dos marcadores discursivos ${ }^{12}$, que são expressões linguísticas cuja função é facilitar o processamento do discurso, os elementos introdutores de tópico fazem parte do DP tópico, como se nota nos exemplos a seguir:

(15) a. ... éh éh éh a respeito de vias públicas então vamos falar em:: mais em estradas... do que vias in::ternas dentro da cidade né?... então:: como eu disse a vocês na Europa eu não tive muita oportunidade de conhecer a não ser na Alemanha... (NURC-SP, inquérito 137)

b. Em cinco horas de entrevista, o pianista erudito João Carlos Martins toma muitas xícaras de chá inglês, mas responde a poucas perguntas. Guarda uma pausa quase musical antes de cada frase e gesticula muito com as mãos, sem que êsses movimentos coincidam com igual número de palavras. Sôbre sua biografia, por exemplo, apenas algumas notas acompanham um refrão imutável... (VEJA, edição 143, 2 de junho de 1971).

Nos dados do NURC-SP, em um universo de 53 ocorrências, 41 delas não apresentaram expressão introdutora de tópico, enquanto que, dos 56 dados extraídos da VEJA, em apenas 13 casos esse uso não foi constatado. ${ }^{13}$ Tal resultado revela que, apesar de ambos os corpora serem formados por entrevistas, o tipo de veículo parece influenciar o modo de introdução dessas construções.

12 Os marcadores discursivos, no entanto, fazem parte das UDEs e normalmente indicam seu início.

13 Os resultados foram apresentados em números absolutos devido ao pequeno número de ocorrências das referidas construções nos corpora estudados. 
Tabela 2 - Distribuição dos elementos introdutores de TP nos corpora analisados

\begin{tabular}{|llc|c}
\hline \multicolumn{1}{c}{ Distribuição } & \multicolumn{1}{c}{ Introdutor } & $\begin{array}{c}\text { NURC-SP } \\
\text { (\%) }\end{array}$ & $\begin{array}{c}\text { VEJA } \\
\text { (\%) }\end{array}$ \\
\hline Presentes nos dois corpora & n.d. & 77 & 23 \\
& Quanto a & 5,5 & 21 \\
& No caso de & 2 & 7 \\
& Em termos de & 5,5 & 2 \\
& Como & 2 & 4 \\
Presentes só no corpus NURC-SPP & A respeito de & 4 & 0 \\
& Por ocasição de & 2 & 0 \\
Preentes só no corpus VEJA & Falando em & 2 & 0 \\
& Para & 0 & 18 \\
& Em & 0 & 7 \\
& A & 0 & 5 \\
& Com & 0 & 5 \\
& Em questão de & 0 & 2 \\
& Sobre & 0 & 2 \\
& De & 0 & 2 \\
\hline
\end{tabular}

Os resultados apresentados nessa tabela demonstram que, na VEJA, há uma maior variedade de elementos introdutores, notadamente aqueles representados por uma preposição única. Pode-se aventar também a possibilidade de que os três introdutores encontrados exclusivamente nos dados do NURC sejam reflexo do tipo de encaminhamento das entrevistas, com perguntas mais genéricas. Nota-se finalmente que há muito mais dados sem elemento introdutor de TP nos dados do NURC-SP (77\%) do que na revista VEJA (23\%), o que também corrobora a maior fluidez dos dados orais.

Nos dados de DETPs, como esperado, não se observou o uso de elementos introdutores de tópico, apesar de, em alguns casos, poder ser constatada a ocorrência de conectivos (como $e$ ) e de marcadores discursivos (como agora):
(16) Não há mortalidade infantil no Parque e, fato inédito no mundo, houve até aumento da população indígena. E agora essa estrada... Sabe onde é que vai passar a estrada? Exatamente numa aldeia de índios bravos. Imagine êsses índios em contato indiscriminado com os garimpeiros! (VEJA, edição 124, 20 de janeiro de 1971)

A ocorrência de marcadores discursivos demonstra que há uma variedade de relações retóricas que vinculam o constituinte anteposto ao contexto. Essa questão será objeto de análise logo à frente.

Definitude e grau de ativação são aspectos importantes para a identificação do estatuto informacional dos constituintes antepostos no TP e na DETP, já que, de acordo com uma série de textos, os tópicos marcados seriam elementos velhos no discurso e necessariamente definidos ( $c f$. CHAFE 1974, LAMBRECHT 1994, entre outros). Os resultados obtidos a partir do estudo de corpus infirmaram ambas as expectativas, pelo menos no que diz respeito aos constituintes em anteposição pendente. Quanto ao aspecto [ \pm definitude], e olhando somente para os dados da VEJA, foram encontrados 30 dados com constituinte [+definido], incluindo-se aí os pronomes, contra 15 dados com constituinte [-definido], tanto na DETP quanto no TP. Dentre esses, é comum, no português brasileiro, a ocorrência de nomes nus, como em (17a), ou, no caso do TP, de nomes introduzidos pela preposição como. Quanto ao aspecto [ \pm velho ${ }^{14}$, e olhando somente para os dados do NURC-

${ }^{14} \mathrm{Um}$ tópico mais [+definido] parece ser quase sempre dado, pelo menos no sentido de acessibilidade. No exemplo abaixo em que se tem "na questão da plumalha.... os urubus são requintados", a plumalha é um tipo de arte indígena que se relaciona com o tema 'artesanato', que havia sido mencionado logo antes. Por questões de espaço, não incluímos mais informações sobre esta questão.

(i) VEJA: 0 aldeamento é uma transição indispensável para uma integração futura?

ORLANDO: - Ah! Sim, porque há uma diferença total entre os índios em estado de seminomadismo, ORLANDO: - Ah! Sim, porque há uma diferença total entre os indios em estado de seminomadismo, que vivem da coleta e da caça, e os que já estão aldeados. Êstes podem se dedicar já ao artesanato que é um estágio superior. Na questão da plumalha, por exemplo, os Urubus são requintados. Pegam um beija-flor, dissecam um beija-flor e tiras as penas para fazer uma placa muito bonita. (...) 20 de janeiro de 1971). 
SP, encontraram-se 16 dados [+velho] contra 10 [-velho] (DETP), e 20 dados [+velho] contra 13 dados [-velho] no TP. Um caso de DETP com tópico [-velho] é ilustrado em (17b):

(17) a. Já no primeiro ou segundo ano ginasial eu me rebelava contra as coisas que tinha certeza não iam me servir de nada na vida. Trabalhos manuais, por exemplo. Eu achava um absurdo o sujeito passar horas juntando tampinhas de cerveja para fazer um capacho com elas, já imaginou? (VEJA, edição 195, 31 de maio de 1972)

b. \{Documentador: - qual o tipo de filme que a senhora acha que é mais bem aceito pelo público? na sua opinião o que o público mais gosta?... de que tipo de filme?...

Informante: - eu acho que o $\mathrm{p}$ / o o o o público o bom o a a o público de hoje que eu digo...a a a turma a...a mocidade a turma de de brotos eles preferem eu acho que filme de de::...sei lá de corrida eles aDOram filmes de de de muita emoÇAO (NURC-SP, inquérito 234)

Se bem que alguns exemplos de dados com o traço [-velho] possam ser incluídos na categoria intermediária 'acessível', nota-se que os requisitos de definitude e pertença ao conhecimento compartilhado pelos interactantes não são nada mais além de componentes prototípicos ou generalizações da noção de 'tópico'. Portanto, as noções de aboutness ("sobre o que a sentença trata") e de frame ("quadro de referência no qual se desenrola a predicação") parecem ser mais corretas, a fim de explicar tais tópicos.

\subsection{Aspectos qualitativos}

Nesta seção, avaliamos questões mais específicas à classificação das relações retóricas que ligam os constituintes antepostos ao discurso. Como já se antecipa, os constituintes antepostos que consistem nos tópicos pendentes constituem, via de regra, UDEs separadas do restante da frase em que pertencem. Por causa disso, nesse aspecto há duas questões distintas a serem trabalhadas: uma se refere à ligação do tópico com seu contexto; outra diz respeito à ligação do tópico com o comentário que o segue. Começaremos por esse último problema, indo depois tratar daquela questão.

Os dados revelaram que há somente dois tipos de relação retórica que ligam o tópico no TP e na DETP ao seu comentário: enquadramento ou atribuição.

O enquadramento é, de acordo com Müller et al. (2012), uma relação retórica na qual um segmento $\mathbf{A}$ funciona como um introdutor de enquadre, uma espécie de delimitador da proposição expressa no comentário $\mathbf{B}$, que pode ser uma UDE ou UDC, como se nota no exemplo a seguir, anotado discursivamente: ${ }^{15}$

(18) [quem faz teatro // qualquer papel...que lhe seja conferido // ele deve saber interpretar....]_1 [deve gostar uhn::// na peça do:: // deve gostar // se entrosar com o personagem...]_2 [mas [n'O ( ) inspetor]_3 me entrosei um POUco... melhor...]_4 [eu me senti mais eu... dentro do personagem...]_5 [ma::s quanto à aceitação]_6 [NUNca nunca tivemos um problema de... de má aceitação muito pelo contrário...]_7 (NURC-SP, inquérito 161)

\begin{tabular}{l|l} 
Elaboração $(1,2)$ & \\
Contraste $([1,2], 4)$ & a \\
Enquadramento $(3,4)$ & \\
Elaboração $(4,5)$ & \\
Enquadramento $(6,7)$ & | b \\
Resultado (a,b) &
\end{tabular}

${ }^{15} 0$ exemplo (18) é um caso em que há um marcador discursivo mas que não representa uma relação retórica de contraste entre as UDCs $(\mathrm{a}, \mathrm{b})$. 
A atribuição, por sua vez, é uma relação na qual se liga um ato de fala $\mathbf{B}$ ao agente deste ato, que deve ser explícito no segmento A. Esta relação é, muitas vezes, introduzida por um verbo de comunicação, como confirmar, informar, explicar e admitir, como já se mencionou na seção 2. Em outros casos, na UDE contém um elemento introdutor, usualmente para, como é o caso da construção de TP ilustrada abaixo:

(19) [Eu não considero ciência sacerdócio:]_1 [sacerdócio é coisa de padre.]_2 [Ciência é uma profissão que deve ser exercida dignamente como qualquer outra,]_3 [mas não tem prestígio nem valor maior, ético ou intelectual, do que qualquer outra profissão.]_4 [Para mim,]_5 [fazer pesquisa é uma profissão,]_6 [com seu artesanato, com sua invenção, com tudo.]_7 (VEJA, edição 306, 17 de julho de 1974).

\begin{tabular}{l|l}
$\begin{array}{l}\text { Elaboração }(1,2) \\
\text { Contraste }(3,4)\end{array}$ & $\mid$ a \\
Atribuição $(5,6)$ & $\mid$ b \\
Elaboração $(6,7)$ &
\end{tabular}

Comentário (a,b)

O mesmo resultado pode ser encontrado na DETP, caso em que somente a relação retórica de enquadramento foi encontrada: ${ }^{16}$

(20) \{Documentador: - e pruma pessoa que não tem grau de escolaridade quais as chances de trabalho que ela a/... que ela pode achar?\}

${ }^{16}$ Um dos problemas metodológicos envolvidos na análise da DETP em textos orais diz respeito à grande ocorrência, nesse contexto, de reformulações, que podem vir a ser confundidos com casos de DETP. 0 critério utilizado para identificar uma reformulação foi a ocorrência de mais informação no segundo item do que no primeiro:

(i) lá em Londres fazia frio eu me recordo de ter visto duas moças... de biquini distribuindo uns::... uns panfletos... em:: Trafalgar Square... e::: um guarda um daqueles célebres guardas londrinos foi panfletos... em:: Trafalgar Square... e::: um um guarda
chamar a atenção delas (NURC-SP, inquérito 137)
Informante: - [olha... hoje em dia... está meio difícil isso...]_1 [ela.... // uma pessoa assim sem escolaridade...]_2 [ela vai cair nu::ma faixa de mi/ de salário mínimo...]_3 [e ela precisará... ter... pelo menos um curso de especialização dentro da profissão DEla....___ (NURC-SP, inquérito 251)

$\begin{array}{ll}\text { Elaboração }(1,[2-4]) & \mid \mathrm{a} \\ \text { Enquadramento }(2,3) & \left.\right|^{\mathrm{b}} \\ \text { Narração }(3,4) & \end{array}$

\section{Elaboração (a,b)}

Tanto o enquadramento quanto a atribuição são relações retóricas de subordinação, o que reflete a dependência do comentário face ao tópico de que depende. A partir dessa observação, podemos também analisar a ligação dos constituintes antepostos com o contexto. O que se observa nos dados apresentados acima (e sistematicamente nos dados analisados quanto às relações retóricas) é a existência de relações de subordinação face ao contexto, como é o caso da elaboração e do comentário. 0 único caso que foge a essa generalização é o primeiro apresentado acima, o exemplo (18), pois há uma relação retórica de resultado, considerada de coordenação. No entanto, o tópico aceitação (do trabalho do artista) estava presente na pergunta do documentador, e nesse ponto o informante retoma o fio principal da resposta esperada; portanto, há uma relação de Elaboração (pergunta, b). No caso da DETP, o tópico pode servir para inserir elementos novos no discurso, como se observou em (17b) e em (21) abaixo:

(21) [teatro]_1 [pro camarada juntar o dinheirinho pra:: pro ingresso é meio pesado...]_2 [pe:: às vezes não é:: questão do:: do do indivíduo ter::.... não ter cultura:: elevada]_3 \{texto com interrupções\} [às vezes em estudan::te um rapaz que paga seus estudos com sacrifício]_4 [ele não POde ter dinheiro nunca para ir ao teatro....]_5 
Enquadramento $(1,2)$

Elaboração $(2,3)$

Enquadramento $(4,5)$

Elaboração $(\mathrm{a}, \mathrm{b})$

No caso em questão, o elemento novo foi anunciado na UDE 2 por meio do elemento genérico o camarada. Há, mais uma vez, elaboração entre a UDC em que ocorre a DETP e o contexto, o que redunda numa relação de subordinação. Duarte (1987) não considera que a DETP possa introduzir elementos novos, no entanto, ocorrências como essas nos faz acreditar que, além de indicar a alteração do assunto relacionado com o tópico da sequência anterior, a DETP possa ser utilizada para cumprir essa função textual. Por outro lado, apesar da existência de várias perguntas nos corpora, não se observou que a DETP funcione como uma estratégia de resposta a uma pergunta sobre o tópico, retomando esse mesmo elemento.

\section{Discussão}

Nessa seção, discutimos duas questões teóricas que derivam da discussão dos dados apresentados na seção anterior. A primeira diz respeito à questão das relações retóricas observadas na seção anterior, e a segunda à contribuição textual das construções de DETP e TP para a progressão temática dos textos ou excertos em que são empregadas.

\subsection{As relações retóricas envolvidas no TP e na DETP}

Como já dito, há duas questões relativas às relações retóricas, sendo que a primeira diz respeito à relação entre tópico e comentário, tratada num primeiro momento. Para discutir tal problema, temos de analisar primeiramente a questão da segmentação (porque os tópicos pendentes correspondem a segmentos, em vez de serem parte do segmento que lhes segue). A crítica que se pode fazer a essa decisão metodológica consiste no fato de esses itens, assim como os adverbiais, não serem usualmente classificáveis como proposições, mas sim como modificadores de proposições. Essa questão é mencionada no manual de anotação retórica do inglês de Reese et al. (2007). Eles sugerem que, seguindo uma perspectiva davidsoniana, eventos são entidades espaciotemporais e, de acordo com essa intuição, (alguns) adverbiais destacados poderiam ser considerados como eventos. Essa perspectiva parece fazer sentido a partir do que dizem Charolles \& Vigier (2005): adverbiais deslocados com significado básico espacial ("em Paris") adquirem valor temporal, condicional, e às vezes até mesmo contrastivo, como no exemplo (22b) abaixo (exemplos traduzidos a partir do texto em questão, adaptados de M. Tournier, Les météores):

(22) a. A vida dividida que Eduardo, um gerente de empresas, levava, lhe parecia feliz. Ele se dedicava por completo às exigências da usina e aos cuidados de Maria Bárbara e das crianças em Pierres Sonnantes. Ele voltava a ser o solteiro ocioso e pródigo de sua juventude em Paris. Ele ia deitar tarde e dormia pouco.

b. A vida dividida que Eduardo, um gerente de empresas, levava, lhe parecia feliz. Em Pierres Sonnantes ele se dedicava por completo às exigências da usina e aos cuidados de Maria Bárbara e das crianças. Em $\underline{\text { Paris, }}$ ele se voltava a ser o solteiro ocioso e pródigo de sua juventude. Ele ia deitar tarde e dormia pouco.

Os autores observam ainda que, apesar de estar imediatamente adjacente à esquerda da UDE que compreende a oração independente, o adverbial deslocado pode modificar várias orações (fato que pode ser descrito a partir da noção de 'escopo'): assim, o domínio de aplicação da frase ele ia deitar 
tarde e dormia pouco em (22b) parece se limitar às ocasiões em que ele estava em Paris, fato que não se pode aplicar em (22a).

Ainda sobre essa questão, estendendo o que diz Combettes (2005) para os constituintes deslocados em geral, pode-se imaginar uma semântica para os adverbiais destacados do tipo "em Paris" ou "em 1980" que envolve uma predicação secundária (no sentido de ser dependente de uma predicação principal). Isso não parece absurdo se se comparam esses constituintes com um adjetivo deslocado do tipo "furioso", admitido por Combettes (2005) como sendo um caso intermediário entre uma proposição desenvolvida e uma 'não-proposição': em ambos há um sujeito implícito, que via de regra é correferente com aquele mencionado na UDE que lhe sucede. No que diz respeito a um constituinte como "para mim", o sujeito da predicação seria explícito, pois esse segmento seria correspondente a "eu penso que...".

O problema da inclusão das relações retóricas que ligam os tópicos pendentes a seus respectivos comentários se coloca face ao que propõe a versão original da SDRT, que identifica as relações retóricas como atos de fala. Sobre o Enquadramento, a partir da leitura de textos específicos sobre a questão, como Vieu et al. (2005), nota-se que adverbiais locativos são tomados como sendo primariamente 'novos introdutores de tópico'. De forma resumida, compreende-se que os adverbiais locativos podem ser interpretados no sentido de trajetória ou no sentido de temporal, como se exemplifica a seguir, a partir de dados adaptados desse mesmo texto:

(23) a. Jean chegou à altura de Albi. Não víamos nada da paisagem. Chovia em Toulouse. Em Cordes, a chuva se transformou em granizo, e, dez minutos mais tarde, os trovões começaram.

b. Naquele verão, François casou-se com Adèle. Jean-Louis partiu para o Brasil e Paul comprou uma casa no campo.
No primeiro caso, o enquadramento pode ser reinterpretado como um tipo de Background, pois desencadeia a pressuposição de que os objetos envolvidos na trajetória continuaram seu movimento até o ponto indicado: "em Cordes" equivale a dizer "tendo (Jean) alcançado Cordes". Isso faz sentido se, na SDRT, pressuposições criam constituintes separados, ligados à sentença principal pela relação de Background. O segundo caso, por outro lado, pode ser reinterpretado como uma relação de Elaboração, e o ato de fala em questão parece ser o de anunciar "eu vou descrever para você um evento (possivelmente complexo), ainda a ser especificado, que se localiza dessa forma". ${ }^{17}$ O mesmo tipo de interpretação, ou seja, como subtipo de uma elaboração, pode ser dado à Atribuição, tratada em Reese et al. (2007) como uma relação entre um agente comunicativo e o conteúdo, quando este não é tomado como parte da sequência argumentativa atribuída ao autor do texto. A diferença é que esses rótulos expressam aspectos mais específicos, como a indicação de uma ruptura discursiva e de uma mudança de ponto de vista na estruturação do discurso.

Nesse sentido, os tópicos pendentes se assemelham aos adverbiais de cena que, em termos pragmáticos, podem ser vistos como o mesmo tipo de constituinte, sendo o ordenamento entre tais elementos devido tão somente ao seu escopo relativo. Uma evidência para essa hipótese é que ambos os tipos de tópicos podem ocorrer sem preposição no português brasileiro. ${ }^{18}$

Finalmente, a questão da relação retórica entre o tópico e o contexto pode ser alvo da seguinte análise: os tópicos marcados no TP e na DETP estão em uma relação de subordinação discursiva face ao contexto. Essa

${ }^{17}$ Os autores referem que o adverbial em (24b) pode ser reinterpretado, dentro do contexto, como "aquele verão viu diversas mudança na vida dos nossos heróis", como se encontra no texto citado originalmente, em Kamp \& Rohrer (1983).

${ }^{18}$ Por alguma razão que escapa à nossa compreensão imediata, nos dados só se encontraram casos de TP com uma relação retórica de enquadramento seguido de outro TP com uma relação retórica de atribuição, e não o inverso. 
hipótese se baseia na previsão de Birner \& Ward (1998), segundo a qual constituintes tópicos em estruturas de anteposição são semelhantes a anáforas, por participarem de um conjunto parcialmente ordenado (POSET, em inglês) com uma âncora presente no discurso anterior. Como toda relação anafórica é limitada pela Restrição da Fronteira Direita, se prevê que a UDE que contém o tópico seja hierarquicamente inferior àquela que contém sua âncora ( $c f$. LÓPEZ, 2009). Mesmo quando o tópico se refere a um elemento novo, identifica-se com frequência a existência de uma proposição aberta saliente no discurso, que o tópico satisfaz (um camarada... um mendigo).

\subsection{A progressão temática e o uso do TP e da DETP}

O funcionamento dos tópicos pendentes nos dados revela ainda que seu uso está ligado a um tipo específico de progressão temática. De acordo com Combettes (1983), a progressão temática linear ocorre quando há o desenvolvimento de um tema que se torna um rema e que, por sua vez, poderá ser tema do enunciado seguinte, tornando o texto coerente. No entanto, Combettes (1983) admite que o encadeamento textual pode ocorrer a partir da progressão do tema constante ou da progressão de temas derivados. No primeiro tipo, há diferentes remas que se relacionam com um mesmo tema. No segundo tipo, os temas normalmente derivam de um 'hipertema' que pode se encontrar no começo da passagem em tela ou numa passagem anterior. Esse último tipo parece ser aquele em que está envolvido o tópico pendente.

Desse modo, o hipertema pode ser definido como um tema mais amplo que pode ser desenvolvido a partir de vários outros temas possíveis. A existência de hipertemas, segundo o referido autor, permite a retomada de elementos, o que é fundamental para que a coerência textual seja mantida. Em (24), por exemplo, ao responder uma questão do documentador sobre como seria o funcionamento do comércio nos EUA, o informante opta por tratar das grandes lojas, a partir do hipertema 'comércio'. No entanto, este hipertema se relaciona com o tópico derivado - nesse caso expresso por um TP 'no caso por exemplo da Eletroradiobrás' - que faz parte do poset 'grandes lojas'. Vê-se, portanto, que, no que concerne à progressão textual, houve uma passagem entre um tópico mais amplo para um tópico mais específico.

(24) nos Estados Unidos?... bom... é um comércio::... eu não sei se nós podemos fazer muita distinção com exceção... ou com a ressalva de... dessas grandes lojas que aqui a rigor no Brasil hoje nós só temos...// aqui em São Paulo o Mappin Eletroradiobrás... ah:: mas são::// no caso por exemplo da Eletro/ Eletroradiobrás são:: é uma ramificação de lojas né? (NURC-SP, inquérito 137).

Vale destacar ainda que nem todos os hipertemas precisam ser textualmente explícitos, podendo ser recuperados contextualmente. Em (25), o entrevistado, ao responder uma questão sobre como superar os problemas relacionados à educação, aborda os temas 'sistema educacional', 'sistema de financiamento de pesquisa', 'clima de liberdade e respeito ao pesquisador', 'bom sistema para prever necessidades imediatas'. Ao inserir o tópico pendente tecnologia, nota-se que ele pode ser incluído entre os itens descritos anteriormente, considerados fundamentais para que os problemas educacionais sejam sanados. Assim, a tecnologia não se constitui como um elemento novo, mas como um elemento inferível a partir do hipertema abordado.

(25) Um bom sistema educacional, em quantidade e qualidade, desde o primário até o superior; um bom sistema de financiamento de pesquisas e grandes importâncias que, somadas às do govêrno e de particulares, atinjam 3\% do produto interno bruto; um bom clima de liberdade e 
respeito ao pesquisador e um bom sistema para prever as necessidades imediatas e futuras das pesquisas para o desenvolvimento global do país. Quanto à tecnologia, especificamente, o Brasil poderia adotar uma política semelhante à do Japão, onde o 'know how' e os 'royalties' são negociados em nível de govêrno e as indústrias têm prazos rígidos para desenvolver os seus próprios conhecimentos. (VEJA, edição 98, 22 de julho de 1970).

Nesse sentido, a previsão de Duarte (1987) de que o TP operaria como uma espécie de elemento de transição entre tópicos discursivos distintos se mantém, pois essa construção pode servir de ponte para uma transição entre temas que se relacionam a um mesmo hipertema.

\section{Considerações finais}

A partir da discussão desenvolvida neste trabalho, foi possível constatar, através da análise de dados do corpus NURC-SP e da revista VEJA, que as construções de anteposição pendente, TP e DETP, ocorrem em contextos de uso específicos no português brasileiro, envolvendo uma relação retórica de subordinação entre o tópico e o contexto, e outra relação de subordinação entre o tópico e o comentário, correspondente a um dos seguintes tipos: Enquadramento ou Atribuição. O quadro teórico da SDRT nos permitiu conferir uma descrição mais clara dos tópicos em questão, em vez de nos basearmos em definições prototípicas, do tipo "elemento velho" ou "elemento definido".

Dessa forma, pôde-se confirmar em linhas gerais a caracterização textual do TP e da DETP apresentada em Duarte (1987), que não se baseou em estudo de corpus. No entanto, também se observou que a DETP pode inserir elementos completamente novos no discurso. Além disso, é possível que outras funções textuais se manifestem por meio dessas construções, já que a análise retórica se baseou num grupo dos dados coletados e que outros gêneros textuais não foram analisados.

\section{Agradecimentos}

Agradecemos aos professores Ataliba de Castilho e Sérgio Menuzzi pelos comentários feitos a uma versão preliminar deste trabalho e ao apoio da Fapesp (processos nos 2013/11291-6 - Macedo Costa e 2011/19235-2 Andrade).

\section{Referências}

AFANTENOS, S.; ASHER, N. Testing SDRT's Right Frontier. In: Proceedings of the 23rd International Conference on Computational Linguistics (Coling 2010). 2010. p. 1-9.

ASHER, N.; LASCARIDES, A. Logics of Conversation. Cambridge: Cambridge University Press, 2003.

ASHER, N. et al. Complex discourse units and their semantics. In: Proceedings of Constraints in Discourse. 2011

ASHER, N.; VIEU, L. Subordinating and coordinating discourse relations. Lingua, n. 115, p. 591-610, 2005. http://dx.doi.org/10.1016/j.lingua.2003.09.017

BIRNER, B. J.; WARD, G. Information Status and Noncanonical Word Order in English. Amsterdam: John Benjamins, 1998. http://dx.doi.org/10.1075/slcs.40

BUSQUETS, J.; VIEU, L.; ASHER, N. La SDRT: une approche de la cohérence du discours dans la tradition de la sémantique dynamique. Verbum, v. 23, p. 73-102, 2001.

CALLOU, D. etal. Topicalização e Deslocação à esquerda: sintaxe e prosódia. In: CASTILHO, A. (org.). Gramática do português falado. Campinas: Editora da UNICAMP/FAPESP, p. 315-360, 1993. Vol. III: As abordagens.

CASIELLES-SUAREZ, E. The Syntax-Information Structure Interface. Routledge, 2004.

CHAFE, W. L. Language in Consciousness. Language, v. 50, n. 1, p. 111-133, 1974. http:// dx.doi.org/10.2307/412014 
CHAROLLES, M.; VIGIER, D. Les adverbiaux em position préverbale: portée cadrative et organisation des discours. Langue française, n. 148, p. 9-30, 2005.

CINQUE, G. The Movement Nature of Left Dislocation. Linguistic Inquiry, v. 8, p. 397-412, 1977.

COMBETTES, B. Pour une grammaire textuelle. La progression thématique. Paris: A. de Boeck \& Ducolot, 1983.

COMBETTES, B. Les constructions détachées comme cadres de discours. Langue française, n. 148, p. 31-44, 2005. http://dx.doi.org/10.3917/lf.148.0031

COSTA, J. PB e PE: orientação para o discurso importa? In: Revista de Estudos da Lingua(gem),Vitória da Conquista, v. 8, n. 1, p. 123-143, jun. 2010.

DUARTE, I. A Construção de Topicalização na Gramática do Português: Regência, Ligação e Condições sobre Movimento. Tese (Doutorado) - Universidade de Lisboa, 1987.

GALVES, C. A sintaxe do português brasileiro. Ensaios de Linguística, v. 13, p. 31-50, 1987.

Tópicos, sujeitos, pronomes e concordância no Português Brasileiro. Cadernos de Estudos Lingüísticos, n. 34, p. 7-21, 1998.

GIVÓN, T. Syntax: an introduction. Amsterdam/Philadelphia: John Benjamins, 2001. Vol. II.

ILARI, R. Perspectiva funcional da frase portuguesa. 2. ed. Campinas: Editora da Unicamp, 1986.

KAMP, H.; RÖHRER, C. Tense in texts. In: BAUERLE, R.; SCHWARZE, C.; VON STECHOW, A. (Eds.). Meaning, Use and Interpretation of Language. Berlin: De Gruyter, p. 250-269, 1983. http://dx.doi.org/10.1515/9783110852820.250

LAMBRECHT, K. Information Structure and Sentence Form. Cambridge: CUP, 1994. http:// dx.doi.org/10.1017/CB09780511620607

LÓPEZ, L. A Derivational Syntax for Information Structure. Oxford: OUP, 2009. http:// dx.doi.org/10.1093/acprof:oso/9780199557400.001.0001

MANN, W. C.; THOMPSON, S. A. Rhetorical structure theory: Toward a functional theory of text organization. Text, v. 8, p. 243-281, 1998. http://dx.doi.org/10.1515/text.1. 1988.8.3.243

MÜLLER, P. et al. Manuel d'annotation en relations de discours du projet ANNODIS. ISSN: 1965-0019. CLLE-ERSS - Maison de la Recherche - Université de Toulouse-Le Mirail, 2012.
ORSINI, M. T. Estudo diacrônico das construções de tópico marcado no Português Brasileiro. In: CARVALHO, G.; ROCHA, D.; VASCONCELLOS, Z. (Orgs.). Linguagem: teoria, análise e aplicações. Rio de Janeiro: Programa de Pós-graduação em Letras. UERJ, 2013. ORSINI, M. T. \& VASCO, S. L. Português do Brasil: língua de tópico e de sujeito. In: Revista Diadorim, v. 2, 2007. ISSN 1980-2552.

PONTES, E. O Tópico no Português do Brasil. Campinas: Pontes, 1987.

REESE et al. Reference Manual for the Analysis and Annotation of Rhetorical Structure (version 1.0). 2007. Disponível em: <http://timeml.org/jamesp/annotation_manual pdf>. Acesso: 10 mar. 2015.

URBANO, H. (Org.) A Linguagem Falada Culta Na Cidade de São Paulo. São Paulo: T. A. Queiroz, 1988. Vol. III: Entrevistas (Diálogos Entre Informante e Documentador).

VIEU, L. et al. Locating adverbials in discourse. French Language Studies, v. 15, p. 173-193, 2005. http://dx.doi.org/10.1017/S0959269505002073

Recebido em 22/04/2015

Aceito em $24 / 06 / 2015$ 